\title{
What does it take to look like
}

\section{a woman?}

Eric Plemons:

\section{The Look of a Woman: Facial Feminization Surgery and the Aims of Trans- Medicine}

Duke University Press, 2017. 192 pages. Price: 23,95 USD.

What does it take to look like a woman? As trivial as this question might seem for some, for others it is a matter of living a livable live. While feminist critique, queer subversion, and trans activism have contributed to the destabilisation of gender in many contexts, gender as an everyday norm that makes life (un)livable is alive and well. And while gender as a norm might be said to influence everyone's lives, its regulatory dimensions and (dis)empowering potency are certainly felt more intensely by some people than by others. Looking like a woman might thus be understood as a performative accomplishment with effects for people's well-being since it potentially decides what options someone will have to live the life they envision for themselves.

Eric Plemons' The Look of a Woman: Facial Feminization Surgery and the Aims of Trans- Medicine gives an account of what this accomplishment looks like in the life of trans women and their surgeons. Based on ethnographic fieldwork among women who undergo surgical procedures aimed at feminising their face and among surgeons who offer these procedures, Plemons asks readers to witness what is at stake for everyone involved in the (incomplete) process of creating the look of a woman. Inviting readers to explore this performative space made up of operating rooms, surgical procedures, health care politics, medical histories, trans activism, and trans women's life stories, he uses ethnography to go against "any simple narrative of what this surgery can" and cannot do (p. 20). He immerses readers in the joys and pains and in the (broken) promises and (un)fulfilled dreams of surgery as a gendered and gendering practice with this captivating ethnography.

One of the focal points of Eric Plemons' sensitive ethnography is the term 'recognition'. Offering recognition as an alternative to the concept of passing, Plemons intervenes in debates within trans and gender studies and trans activism about the use of passing as a way to describe and analytically comprehend how gender works (or not). As he argues, recognition "offers a set of analytical tools and stakes that move beyond questions of authenticity and artifice, truth and falseness, 
duplicity and strategy that often structure discussions of passing." (p. 15) Wanting to explicitly avoid thinking within dichotomies of right and wrong and good and bad, Plemons' use of recognition envisions the term both as an ontological description of how to comprehend trans women's efforts to be seen and understood as the women they want to be as well as an epistemological device for scholars attending to gender as an analytical object. As such an onto-epistemological concept, Plemons uses recognition to "see FFS (facial feminisation surgery) as suspended in tensions" (p. 15) rather than situating it as either success or failure since "[r]ecognition is a dynamic process of exchange, not a negotiation of 'true' and 'false' identities." (p. 91)

With such a focus on recognition, the book's different chapters provide a chronology of facial feminisation surgery (FFS) in at least a triple sense. While they take the reader from the origins of the procedure, its refinement and development as part of US trans medicine, to its practice and commercialisation today through the lens of its practitioners, the chapters also attend to facial feminisation surgery as the endeavour of women wanting to be recognised the way they envision themselves while also being members of a community divided by the question whether facial feminisation surgery in its current form is just and whether it is helpful for trans activism. Yet the book is also a chronology of how ways of imagining gender in medical practice and feminist thought have developed with, through, and sometimes against the efforts of trans people and their surgeons.

In chapter one, Eric Plemons retraces the history of facial feminisation surgery by going into detail with how its inventor, the surgeon Douglas Ousterhout, developed the procedure. Providing insights into the conceptual thought universe of the surgeon and critically examining the research and concepts Ousterhout uses to develop facial feminisation surgery, Plemons shows how influential ideas about the performativity of gender actually were in the reformulation of trans surgery. Chapter two compares different approaches to providing care and expertise for women seeking facial feminisation surgery. Contrasting Ousterhout's approach with that of another surgeon, Joel Beck, Plemons marks the shift in trans-surgery from operating on a pathologised body towards operating on a body to reach its fullest potential. As Plemons then goes on to show in chapter three, the success of facial feminisation surgery and the shift explored in chapter two heavily depend on the mobilisation of affect in the relations between surgeons and patients. While some might say surgical procedures are effective in and of themselves as medical interventions, Plemons argues that the effectiveness of facial feminisation surgery also depends on the affective dimensions of the clinical encounter between surgeon, patient, and the staff that take care of patients before and after surgery. In the book's fourth chapter, Plemons visits the societal, political, and activist contexts in which facial feminisation surgery as a social technology is embedded. What emerges here is the complexity of recognition that goes beyond a simple decision of passing as a woman or not. The political economies of recognition take centre stage here, reminding the reader that individual dreams and hopes are, for good and bad, always connected to larger collectives. Chapter five takes the reader into the operating room to witness how facial feminisation surgery is actually done. While all chapters are proof of Plemons' ethnographic skills, it is in this chapter that the strengths of his ethnographic analysis and writing become beautifully visible. Weaving his own ethnographic positionality sensitively together with the violence of the procedure as well as with the women's visions of their future selves, this chapter grounds scholarly discussions of the malleability of gender in the ethnographic account of bodies and identities being worked on, or as he writes himself: "Projects of political and philosophical imagination are vital to our collective spirit; they give us something to look forward to, a future worth working for. But the present isn't only a moment to be surpassed. Being present with Rosalind and other FFS patients meant remaining in complexity and contradiction without looking for relief and letting the gravity of this radical surgery have its way." (p. 133) In chapter six, the narratives of women having undergone 
facial feminisation surgery are in focus as Plemons tells the stories of three patients - Rachel, Jill, and Zoe. While Rachel's and Jill's stories are filled with optimism about the transformative potential of the surgery, Zoe's account is characterised by disappointment about its failure. Yet no matter how the individual woman judges the accomplishment of looking like a woman, their stories remind us that recognition is more complex than the claim that it is realised through a certain medical intervention. Recognition is a process as part of which (trans)gendered bodies are actualised in the social encounter.

The Look of a Woman: Facial Feminization Surgery and the Aims of Trans-Medicine is a superb ethnographic account of gender in the making. Eric Plemons has given us a riveting book about the enticing force of gender - as part of medical practice, health politics, activism, and not least people's visions of themselves. And as such this book belongs on the syllabi and reading lists of anyone in gender studies.

SEBASTIAN MOHR, Senior Lecturer in Gender Studies, Centre for Gender Studies, Karlstad University. 